\title{
Medicamentos genéricos no Brasil: impactos das políticas públicas sobre a indústria nacional
}

\author{
Generic drugs in Brazil: \\ impacts of public policies upon the national industry
}

Cristiane Quental ${ }^{1}$

Jussanã Cristina de Abreu ${ }^{2}$

José Vitor Bomtempo ${ }^{3}$

Carlos Augusto Grabois Gadelha ${ }^{1}$

${ }^{1}$ Escola Nacional de Saúde

Abstract This paper echoes recent works of Abras$\mathrm{CO}^{1}$, Gadelha ${ }^{2}$ and Guimarães ${ }^{3}$ emphasizing the need for a better integration between health policies and industrial development and innovation policies as the only way to keep the economic benefits generated by health expendituresin the country instead of letting them escape through imports and threaten the continuity of the social policy by growing trade deficits. Although presenting the generic drug policy as a successful case in integrating social policies aimed at a better access to quality drugs for the population with economic policies aimed at industrial development, this paper discusses the impacts and limitations of the referred policy in a dialog with Abreu's analysis of industrial competitiveness in the Brazilian generics industry.

Key words Public policies, Drug policy, Generic drugs
Resumo 0 presente artigo faz eco a trabalhos recentes da Abrasco스. Gadelha ${ }^{2}$ Guimarães ${ }^{3}$, que enfatizam a necessidade de uma maior integração entre as políticas vol tadas para o desenvolvimento do sistema desaúdee aquelas voltadas para a promoção do desenvolvimento industrial e da inovação, como forma de garantir para o país os benefícios econômicos gerados pel os gastos em saúde, assegurando a continuidade da política social, num círculo virtuoso. Embora apresente o caso dos medicamentos genéricos como uma experiência de sucesso na integração das políticas sociais voltadas para um maior acesso da população a medicamentos com qualidade garantida, com as políticas econômicas voltadas para o desenvolvimento industrial, discute os impactos e as limitações da política dialogando com a análise da competitividade da indústria de medicamentos genéricos brasileira realizada por Abreu 4 . Palavras-chave Políticas públicas, Política de medicamentos, M edicamentos genéricos 
Introdução

0 presente artigo faz eco a trabalhos recentes ${ }^{1-3}$ que enfatizam a necessidade de uma maior integração entre as políticas voltadas para o desenvolvimento do sistema de saúde e aquelas voltadas para a promoção do desenvolvimento industrial e da inovação, como forma de garantir para o país os benefícios econômicos gerados pelos gastos em saúde.

As políticas de saúde eas políticas industriais enfrentam claros conflitos, já em seus objetivos primeiros: o governo, ao mesmo tempo em que busca a contenção dos custos para fazer frente aos orçamentos crescentes da saúde, é responsável pelo apoio à indústria, dentre elas as da saúde, como apontam Vandergrift et al ${ }^{5}$. Sua integração, entretanto, é tão delicada como necessária, dado que o segmento de assistência à saúdee os segmentos industriais que 0 abastecem são elos de uma mesma cadeia produtiva. A favor desta integração está ainda o fato de o governo desempenhar papel forte na dinâmica desses setores, através da prestação de serviços assistenciais, da compra de bens e serviços e das atividades regulatórias, que delimitam as estratégias dos agentes econômicos, como observa Gadelha².

Alguns países conseguiram avançar na elaboração de políticas integradas, potencializando os benefícioseconômicosesociaisadvindos das ações empreendidas. No Brasil, entretanto, estas duas dimensões não são articuladas e a demanda originada dos avanços na área da saúde tem sido atendida por produtores estrangeiros, traduzindo-seem crescentes déficits comerciais queameaçam o avanço do próprio sistema de saúde?.

Este artigo apresenta o caso dos medicamentos genéricos como uma experiência de sucesso na integração das políticas sociais voltadas para um maior acesso da população a medicamentos ea medicamentos com qualidadegarantida, com as políticas econômicas voltadas para o desenvolvimento industrial. Chama atenção, entretanto, para suas limitações, ao dialogar com a análise da competitividade da indústria de medicamentos genéricos brasileira realizada por $\mathrm{Abreu}^{4}$. Esta análise édesenvolvida segundo duas dimensões: uma relativa à estrutura industrial e outra relativa ao perfil das empresas que a compõe.

A partir da identificação dos fatores de competitividadenestas duas dimensões, discute-se os impactos e as limitações das políticas públicas para o desenvolvimento da indústria nacional.

\section{Osmedicamentos genéricos}

Até o final da década de 1990, o mercado brasileiro oferecia dois tipos de medicamentos:

(a) os medicamentos lançados originalmente pelas empresas líderes da indústria mundial, com marca própria e de conhecimento disseminado, registrados junto ao órgão federal responsável pela vigilância sanitária, cuja eficácia, segurança e qualidade foram comprovados cientificamente. No Brasil, estes medicamentos são denominados de "inovadores", se bem que esta denominação seja errônea e pouco precisa, uma vez quea maioria se encontra fora do período de proteção patentária, sendo, portanto, fruto de esforços de inovação já explorados num passado remoto; e

(b) cópias destes medicamentos, chamados "similares", contendo os mesmos princípios ativos, na mesma concentração e forma farmacêutica que o medicamento inovador, sendo normalmente lançados por empresas de porte médio e pequeno, com alta predominância de capital nacional, firmas marginais do ponto de vista da liderança e da estrutura empresarial, que lançam marcas próprias e que competem nas "franjas" do mercado farmacêutico.

Com o intuito de assegurar a oferta de medicamentos de qualidade e baixo custo no mercado e de fomentar 0 acesso da população a estes medicamentos, são estabelecidos, pela Lei $n-9.787$ / $99^{6}$, osmedicamentos genéricos. Sua intercambialidade com o medicamento de referência é assegurada por testes de equivalência farmacêutica e bioequivalência realizados por laboratórios credenciados pela Agência Nacional de Vigilância Sanitária (ANVISA) e sua qualidade pelo monitoramento das unidades produtivas quanto ao atendimento das Boas Práticas de Fabricação BPF, de acordo com a RDC n' $210 /$ AN VISA? $^{7}$.

A lei dos genéricos obriga queas aquisições de medicamentos e as prescrições médicas, no âmbito do SUS, adotem a denominação do princípio ativo; que, nas compras do SUS, sedê preferência ao medicamento genérico quando houver igualdade de preço e demais condições de aquisição; obriga a ANVISA a editar, periodicamente, a relação dos genéricos já registrados no país.

Ao lado disso, 0 apoio do governo aos medicamentos genéricos, através do esclarecimento da população e da sua promoção junto aos seus diversos públicos e junto às farmácias, levou a seu sucesso no mercado. 0 varejista, pressionado pela demanda, abriu espaço para os medicamentos genéricos ${ }^{4}$. 
De forma a facilitar a identificação destes medicamentos, adotou-se embalagem externa personalizada, criando-se um padrão para as embalagens de todos os medicamentos genéricos comercializados no mercado brasileiro. Segundo a legislação ${ }^{8}$, na embalagem externa deve constar uma tarja amarela com a grafia da mensagem "M edicamento Genérico" ea letra "G" em destaque.

No que tange aos medicamentos similares, a ANVISA vetou, a partir de setembro de 2002, a comercialização daquel es cujas embalagens apresentassem apenas o nome do principio ativo?.

Além disso, 0 apoio à indústria nacional permitiu que empresas brasileiras ganhassem competitividade e, pela primeira vez em décadas, aumentassem sua participação nestemercado, mantendo no país os empregos e a renda gerados. Entre outras ações, foram abertos pelo Banco $\mathrm{N}$ acional de Desenvolvimento Econômico eSocial (BNDES), a partir de 2001, dois programas de apoio às atividades da indústria farmacêutica de medicamentos genéricos, a saber: apoio à produção e registro de medicamentos e apoio à importação de equipamentos. As empresas nacionais foram as principais beneficiadas com as linhas de financiamento do BNDES, dentre elas as líderes de mercado de medicamentos genéricos: M edley, EMS Sigma Pharma, Eurofarma e Biosintética, que modernizaram suas plantas industriais e incrementaram a capacitação tecnológica, fazendo frente às empresas de grupos multinacionais instaladas no país, como verificado por Abreu ${ }^{4}$.

Do ponto de vista da política tecnológica, a iniciativa mais relevante se refereà montagem de toda uma infra-estrutura de pesquisa e serviços tecnológicos para apoio a esta indústria através da capacitação de instituições públicas e privadas para a realização de ensaios de equivalência farmacêutica e bioequivalência, embora esta estrutura ainda seja frágil em algumas áreas.

Ampliação da oferta de genéricos: benefícios para o consumidor e desafios para a saúde pública

$\mathrm{Na}$ análise econômica convencional, a regulação do mercado, seja por instrumentos diretos (por exemplo, pela ação de agências reguladoras) ou por medidas queincidem na estrutura industrial e nas estratégias competitivas, como éo caso do estímulo à produção degenéricos, pode beneficiar os consumidores em termos da redução de preços e na quantidade consumida. Assim sen- do, 0 objetivo da política seria obter ganhos para a população em dois níveis. Por um lado, o oferecimento de medicamentos mais baratos, com garantia de qualidade, ampliaria o excedente do consumidor. Por outro, na medida em que a elasticidade preço da demanda fosse elevada, haveria ampliação do consumo e, por conseqüência, do conjunto da população que tem acesso a tratamento por intermédio de medicamentos ${ }^{10}$.

Efetivamente, os preços dos medicamentos genéricos mantiveram-secerca de $40 \%$ inferiores aos preços dos medicamentos de referência entre os anos de 2000 e 2003 conforme a ANVISA ${ }^{11}$. Tal parâmetro como preço deentrada foi induzido pelo governo quando da inserção desses produtos no mercado ${ }^{10}$. Para alguns casos, os resultados seriam significativamente mais positivos ${ }^{11}$.

A evolução da produção de medicamentos genéricos foi expressiva, partindo de 2,7 milhões de unidades em junho de 2000 para 200 milhões de unidades em dezembro de 2005,12. Embora grande parte deste crescimento tenha se dado às expensas dos medicamentos de referência (Figura 1 ), segundo $\mathrm{H}$ asen $\mathrm{clever}^{10}$, haveria ainda correlação positiva e estatisticamente significativa entrea introdução degenéricos ea taxa decrescimento da quantidade demedicamentos vendida, observada dentro de cada conjunto de medicamentos com princípios ativos iguais e formas de apresentação semelhantes. Em conclusão, teria havido não só redução de preços, como também aumento do consumo.

Todavia, em se tratando de uma atividade industrial que está inserida no Sistema $\mathrm{N}$ acional de Inovação e no Sistema de Saúde ${ }^{14,2}$, torna-se necessário inserir outras dimensões relacionadas ao seu impacto nas condições de saúde e na capacitação dinâmica dos agentes locais. Em relação ao sistema de saúde, isto requer uma análise da forma como os produtos estão sendo priorizados para sua introdução no sistema, público ou privado. Ou seja, a simples expansão do consumo e a redução de preços podem ter pouco impacto nas condições de saúde se estiverem ausentes critérios cientificamente baseados de avaliação tecnológica. Do ponto de vista do Sistema de Inovação, énecessário pensar se as atividades industriais que estão sendo desenvolvidas trazem ben efícios para o aprendizado e para as estratégias locais de inovação, uma vez que a mai or fragilidade do complexo industrial da saúde é a reduzida base local e empresarial de inovação.

Feitas estas qualificações, uma análise que se restrinja apenas às dimensões econômicas convecionais mostra uma situação que está evoluin- 
Figura 1. Evolução da participação dos medicamentos genéricos - M US\$ (2001 - 2005).

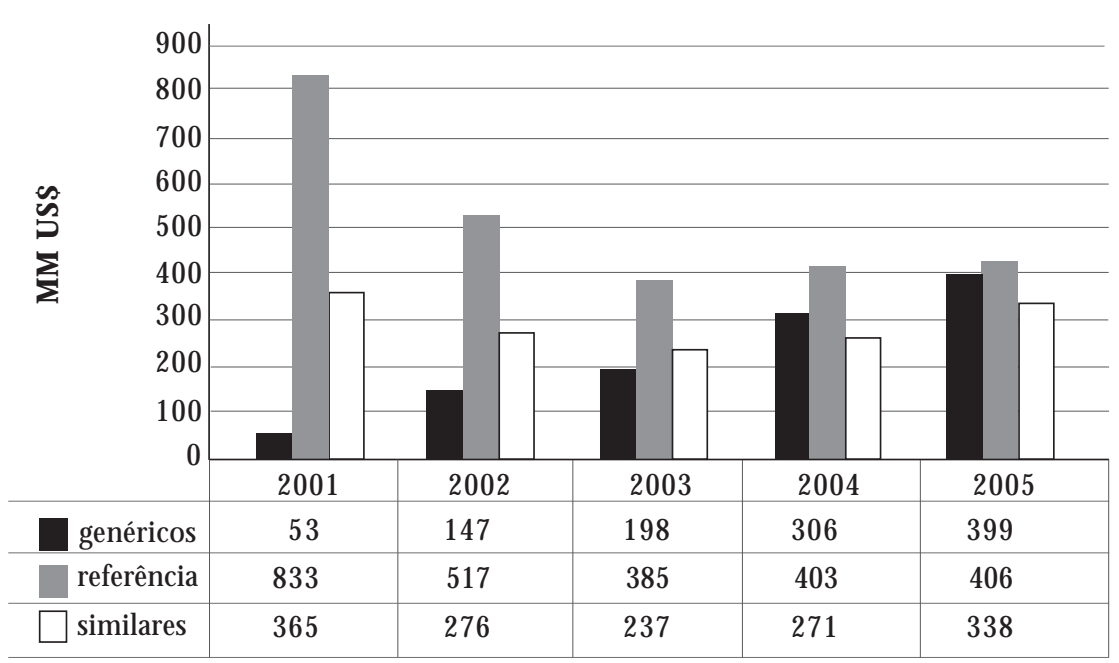

Fonte: IM SH ealth ${ }^{13}$.

do de modo favorável eque pode ser a base para ações mais abrangentes relacionadas aos objetivos constitucionais de universal ização do acesso e de eqüidade na estruturação do Sistema Ú nico de Saúde no Brasil e à competitividade local em termos dinâmicos e com foco na inovação.

\section{Fortalecimento da indústria nacional}

A mobilização da indústria aos incentivos governamentais foi rápida. A Figura 2 apresenta a evolução do número de registros de medicamentos genéricos e das empresas atuantes na indústria. O número de empresas passou de dezesseis em dezembro de 2000 para 66 em maio de 2006 e as apresentações comercializadas, de 563 para 10.126 no mesmo período.

As empresas pioneiras na indústria de genéricos no Brasil foram empresas nacionais e se consolidaram rapidamente. Segundo a Tabela 1 , dentre as cinco empresas que lideravam a posição no mercado no período de agosto de 2002 a agosto de 2005, quatro eram nacionais: Medley, EM S Sigma Pharma, Biosintética e Eurofarma, respondendo por cerca de $73 \%$ de participação do mercado brasileiro de medicamentos genéricos em valor no período. As dez maiores empresas concentravam $96 \%$ do mercado.

0 sucesso dos medicamentos genéricos no Brasil levou, inclusive, a empresa EM S Sigma
Pharma a figurar entre as dez empresas líderes da indústria farmacêutica total brasileira, dominado por multinacionais, ao lado da Aché (Tabela 2).

A exigência dos estudos de equivalência farmacêutica (nos quais se procura mostrar que 0 medicamento genérico contém o mesmo fármaco, na mesma quantidade e forma farmacêutica que o medicamento de referência) e bioequivalência (nos quais se procura mostrar que o medicamento genérico eo medicamento de referência, ao serem administrados na mesma dose e nas mesmas condições experimentais, não apresentam diferenças estatisticamente significativas em relação à biodisponibilidade, avaliada a partir da velocidade e extensão de absorção do princípio ativo, a partir de sua circulação sistêmica ou sua excreção na urina) levou à criação de toda uma infra-estrutura de serviçostecnológicos para apoio a esta indústria.

Os centros de equivalência farmacêutica fazem parte da Rede Brasileira de Laboratórios Analíticos em Saúde (Reblas), rede de laboratórios públicos e privados credenciados pela ANVISA para apoio ao controle de produtos sujeitos à vigilância sanitária, que demonstram competência técnica para realizar os estudos e análises a que se propõem e atendem aos princípios fundamentais da gestão da qualidade analítica e as Boas Práticas de Laboratórios (BPL). Os centros de equivalência farmacêutica certificados em 
Figura 2. Evolução do mercado de medicamentos genéricos (Fev/2000 - M ai/2006): empresas x apresentações.

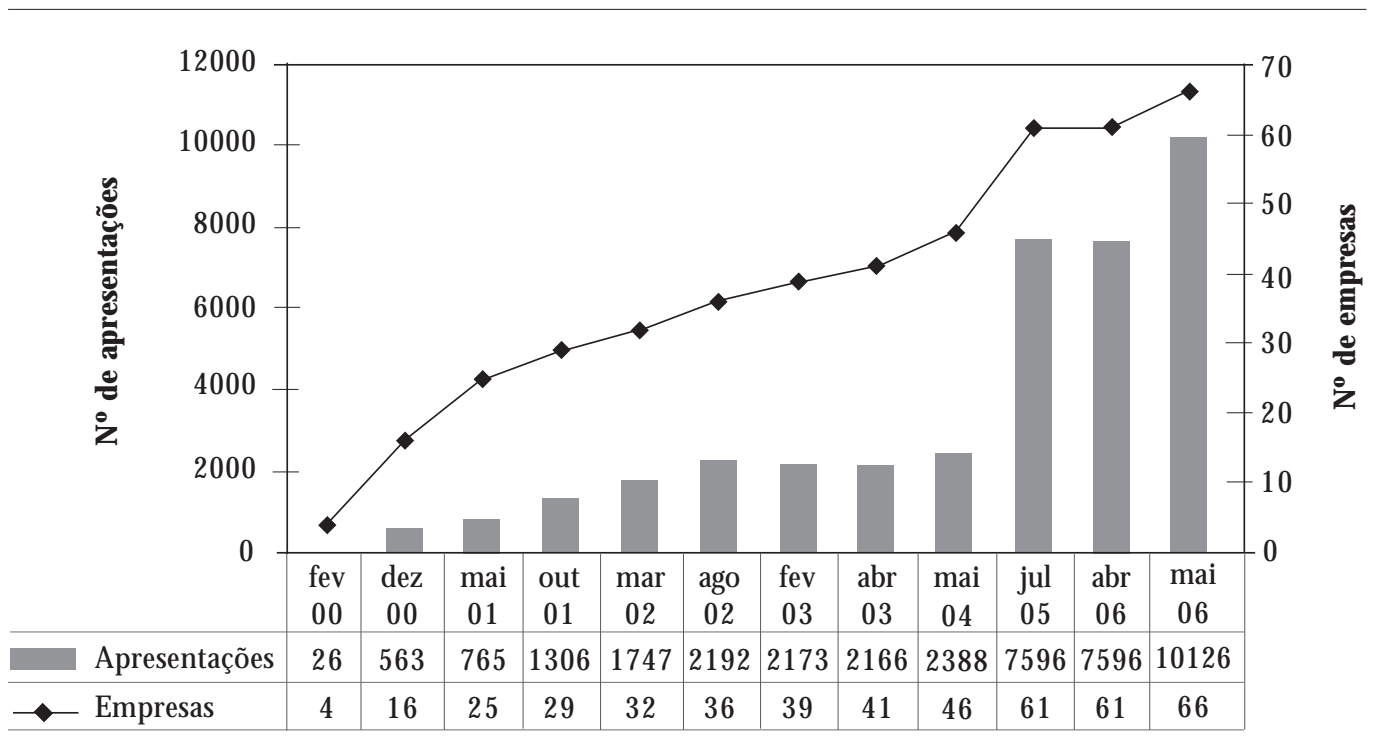

Fonte: ANVISA ${ }^{11}$

Tabela 1. Participação das empresas no mercado de medicamentos genéricos (Vendas: ago/02 - ago/05).

\begin{tabular}{llcccc}
\hline & \multirow{2}{*}{ Empresas } & \multicolumn{3}{c}{ Participação (\%) } \\
\cline { 3 - 5 } & & ago/02 & ago/03 & ago/04 & ago/05 \\
\hline 1 & M edley & 27,46 & 26,44 & 27,65 & 29,13 \\
2 & EM Sigma Pharma & 18,05 & 19,91 & 21,64 & 25,91 \\
3 & Biosintética & 17,92 & 13,00 & 12,44 & 12,42 \\
4 & Eurofarma & 11,12 & 9,99 & 10,17 & 9,05 \\
5 & Ranbaxy & 10,30 & 8,80 & 7,20 & 5,13 \\
6 & Novartis & 4,31 & 4,70 & 4,75 & 3,97 \\
7 & Merck & 2,74 & 3,56 & 3,35 & 2,82 \\
8 & Hexal do Brasil & 1,58 & 1,74 & 2,17 & 1,92 \\
9 & Germed & 0,17 & 0,28 & 0,26 & 1,78 \\
10 & Mepha & 0,07 & 0,49 & 1,27 & 1,30 \\
& & 93,00 & 88,91 & 91,20 & 93,43 \\
\hline
\end{tabular}

Fonte: IM S13.

junho de 2006 chegavam a 39, em sua maioria pertencentes a empresas farmacêuticas ${ }^{15}$.

$\mathrm{N}$ o que diz respeito à bioequivalência, em junho de 2006 eram 26 os centros nacionais certificados e três aqueles em processo de certificação. Em virtude dos gargalos ainda existentes nessa área no Brasil, a ANVISA certifica também centros estrangeiros, contando com sete centros estrangeiros certificados e três em processo decertificação no mesmo período (metade deles localizados na Índia). Os centros são certificados a partir da comprovação de cumprimento das normais nacionais e internacionais de pesquisa clínica edos regulamentos técnicos vigentes pertinentes aos ensaios de biodisponibilidade/bioequivalência emitidos pela ANVISA ${ }^{16}$. A participação dos centros públicos- localizados em universidades ou hospitais universitários - é maior neste segmento, chegando quase a $50 \%$ do número total de centros nacionais credenciados.

A consolidação desta infra-estrutura técnica de apoio à indústria já está permitindo a extensão 
Tabela 2. Principais empresas da indústria farmacêutica brasileira, mercado total, ano 2003 faturamento (US\$ mil).

\begin{tabular}{cll}
\hline Ranking & \multicolumn{1}{c}{ Empresa } & $\begin{array}{c}\text { Faturamento } \\
\text { (US\$ mil) }\end{array}$ \\
\hline 1 & Pfizer & 274.518 \\
2 & Aventis Pharma & 239.815 \\
3 & Novartis & 237.412 \\
4 & Aché & 209.792 \\
5 & Roche & 168.334 \\
6 & Ems Sigma Pharma & 160.754 \\
7 & M erck Sharp \& Dohme & 136.665 \\
8 & Schering-Plough & 136.494 \\
9 & Schering do Brasil & 136.068 \\
10 & Boehringer & 133.261 \\
\hline \multicolumn{2}{l}{ Total das dez maiores } & 1.424 .295 \\
M ercado total & 4.593 .319 \\
\hline
\end{tabular}

Fonte: IM S13.

aos medicamentos similares da exigência quanto à realização detestes de equivalência farmacêutica ebiodisponibilidaderelativa, atéentão só cabíveis para os medicamentos genéricos. Com isso, amplia-se o controle da qualidade a todos os medicamentos comercializados no Brasil.

\section{Alcance e limites da política de genéricos}

Do ponto devista da política industrial, o impacto da política de genéricos foi positivo, tendo representado um nicho ou "janela de oportunidade" para a promoção da competitividade das empresas brasileiras.

Promover a competitividade das empresassignifica, segundo Ferraz et al. ${ }^{17}$, ajudá-las a antecipar e se adaptar aos fatores críticos de sucesso em seu mercado, obtendo, assim, maior lucratividade e recursos para crescer. A capacidade de as firmas competi rem nos mercados pode ser fortalecida se o regime de incentivos e regulação a que estão sujeitas for eficaz. O s incentivos visam aumentar a capacidade de resposta das empresas diante dos desafios impostos pela economia e as regulações buscam condi cionar as suas condutas em di reções socialmente desejáveis. [...] Tomadores de deci são públicos e privados devem, então, entender quaisfatores, devidamente incentivados ou controlados, re sultarão em maior capacidade de resposta aos desafios competitivos ${ }^{17}$.

A análise do caso dos medicamentos genéri- cos empreendida por Abreu ${ }^{4}$ mostra que as empresas nacionais analisadas tiveram plenas condições de responder aos desafios que Ihes foram colocados:

- a competição éfortemente baseada em preço, sendo importante a capacitação em produção, para alcançar os menores custos. As empresas líderes na produção de medicamentos genéricos dominam as tecnologias de formulação, dispõem de equipamentos novos e utilizam a capacidade produtiva de forma racional.

. 0 acesso aos canais de distribuição é uma das mais fortes barreirasà entrada de novos competidores, por serem bastante concentrados (de acordo com Langshwager ${ }^{18}$, os vintemaiores distribuidores concentram $89 \%$ do negócio). 0 fato de as empresas líderes na indústria de medicamentos genéricosterem entrado na indústria através da produção e comercialização de medicamentos similares facilitou 0 acesso aos canais de distribuição de seus medicamentos genéricos.

. o pioneirismo no lançamento de um novo medicamento genérico no mercado também é considerado um fator de competitividade empresarial. As empresas acreditam que aquelas que chegam primeiro ao mercado obtêm lucros superiores às demais. As próprias empresas nacionais atribuem sua posição de liderança no mercado brasileiro à vanguarda de atuação no segmento no ano de 2000.

\section{Limites}

O sucesso, entretanto, parecelevar a uma acomodação.

Um ponto comum em todas as empresas analisadas é a perspectiva positiva quanto à expansão da indústria de medicamentos genéricos no Brasil e ao aumento da participação desta no mercado total daindústria demedicamentos. Em linhas gerais, pretendem aproveitar o boom do mercado com a configuração atual e não vislumbram modificações no modo de encarar o desenvolvimento deste mercado no Brasil, embora acreditem que a competição deverá se acirrar devido à entrada de novos competidores de atuação global, tais como a Apotex, Ranbaxy, Cinfa, Hexal e Rathiophama, e à estabilização do número de competidores para os próximos anos. Coloca-se como o grande desafio para se manterem na liderança com a entrada desses competidores a construção de estratégias empresariais cada vez mais agressivas, como as deles.

Ressalte-se que o porte das empresas nacio- 
nais é marginal face àquele das empresas de atuação global. Como exemplo: as vendas da empresa israelense Teva Pharmaceutical no ano de2002, que foram de US\$ 2,5 bilhões ${ }^{19}$, comparando-se com os US $\$ 61$ milhões da empresa que mais vendeu no mercado nacional no período, a M edley. Além disso, tem ficado patente nos últimos anos um processo de mudança estrutural na indústria mundial de genéricos, que tem levado a um aumento expressivo do porte dos competidores. Os movimentos de aquisição têm sido freqüentes e passaram a incluir iniciativas dos competidores líderes da indústria farmacêutica. Cite-se a consolidação pela N ovartis da sua divisão de genéricos Sandoz, que incorporou competidores importantes como Hexal e Eon Labs, tornando-se, ao lado da Teva Pharmaceutical (que também realizou aquisições importantes recentemente), as duas maiores empresas da indústria com vendas, cada uma delas, da ordem de US $\$ 5$ bilhões ${ }^{20,21}$. Faz-se necessário uma revisão das suas estratégias de negócio para impedir que as empresas de atuação global não invertam o jogo até agora dominado pelas empresas nacionais.

Ainda assim, as empresas analisadas não pretendem mudar seu padrão de atuação:

. com exceção das duas maiores empresas nacionais, a M edley e a EM S Sigma Pharma, as empresas entrevistadas não pretendem exportar medicamentos genéricos etal fato foi atribuído à falta de um estímulo para a exportação, devido ao grande número de tributos que as empresas nacionais precisam desembolsar, ao risco envolvido em uma estratégia internacional eàs barreiras sanitárias existentes entre os países. M edley e EMS Sigma Pharma iniciaram sua inserção no mercado europeu, que responde por US\$10 biIhões/ ano de medicamentos genéricos, através de Portugal. Para isto, as empresas precisam adequar os produtos e as instalações produtivas dentro dos requisitos dos órgãos de vigilância sanitária dos países que pretender comercializar. $\mathrm{Na}$ EM S Sigma Pharma, o processo encontra-se na fase de certificação da planta pela Infarmed, órgão de vigilância sanitária português, mas a empresa já distribui produtos em Portugal através da divisão Germed Ltda. desde setembro de 2004. A M edley já possui contratos para exportação de genéricos para a Venezuela, M éxico, Argentina eChile $e^{22}$.

. não pretendem verticalizar a produção, produzindo matérias-primaseintermediários desíntese (indústria farmoquímica), um contrastecom as empresas especializadas em medicamentos genéricos de atuação global, como por exemplo, a Ranbaxy e a Teva. A verticalização é vista com receio pelas empresas, que alegam que o investimento para competir em porte com as empresas já atuantes no segmento farmoquímico é proibitivo para as empresas líderes da indústria de medicamentos genéricos no Brasil.

- poucas das empresas analisadas possuem ações efetivas para atuar e ser reconhecidas como empresas produtoras de medicamentos inovadores. As demais pretendem continuar como produtoras de genéricos. Porém, todas as empresas buscam ser pioneiras no lançamento de medicamentos genéricos de maior valor agregado.

Os limites da política ficam, assim, claros:

. o jogo competitivo pode virar dentro da indústria: os produtores de atuação global podem passar a se beneficiar mais do crescimento do mercado brasileiro. Para quetenha efeito contínuo, o estímulo tem que ser contínuo. Deve, dessa forma, adequar-se à fase de desenvolvimento e ao momento competitivo da indústria. Talvez neste momento, 0 apoio às empresas do segmento pudesse estar voltado para as exportações, por exemplo. Mas a falta de apoio adequado pode levar a uma situação vantajosa para os competidores globais que ora se instalam no Brasil na apropriação dos benefícios gerados pelo crescimento do mercado brasileiro.

. uma indústria de genéricos consolidada pode ser uma condição para o estabelecimento deuma produção nacional defármacos, segmento priorizado pela atual política industrial. 0 ge nérico estimula a produção do fármaco e diminui as importações. A empresa multinacional vai trazer o fármaco da sua matriz ou de al guma filial. A nacional équevai comprar o fármaco do produtor brasileiro23.

Mas, embora necessário, o incentivo aos genéricos, por si só, não incentiva os fármacos, uma vez que as empresas nacionais de genéricos não se dispõem a entrar nesse segmento, bastante diferente daquele em queatuam atéo momento.

- 0 incentivo aos genéricos também não toca na questão da inovação, do desenvolvimento de novas moléculas, o cerne da competição na arena mais nobree lucrativa da indústria farmacêutica. Ao contrário, não há nem mesmo a possi bilidadedeinovação incremental em genérico, pois eledeixaria deser "cópia idêntica" do medicamento de referência, se bem que a própria produção do genérico constitua uma inovação para a empresa produtora.

$\mathrm{N}$ ão se pode apostar que se incentivando os medicamentos e as empresas de genéricos estas se engajariam no desenvolvimento de atividades 
de $P \& D$ voltadas para o desenvolvimento de novas moléculas - poucas têm essa intenção. $A$ arena competitiva é outra, os fatores críticos de sucesso são outros e as empresas de genéricos não se sentem nem capacitadas nem atraídas a atuar nessa outra arena. O s incentivos para a inovação têm que ser específicos.

Mas essas poucas que estão começando a investir em $P \& D$ buscando a inovação merecem ser incentivadas, pois são os casos mais promissores.

\section{Conclusões}

Todas as evidências recolhidas apontam para 0 sucesso da política brasileira de incentivo à produção final dos medicamentos genéricos, sobretudo no que diz respeito ao seu impacto sobre o desenvolvimento da indústria nacional e a montagem de uma infra-estrutura de serviços tecnológicos de apoio. As empresas nacionais tiveram condições de responder aos desafios competitivos e lideraram a competição na indústria, ganhando parcela de mercado no segmento de genéricos. Esta política, entretanto, tem limites, não prevendo novos desenvolvimentos para a indústria farmacêutica nacional. A inclusão do setor de fármacos na política industrial foi, nesse sentido, o passo seguinteda política. No presente, as indicações de priorização da área farmacêutica são evidentes, retomando-se a idéia de colocar a indústria como um setor-chave da competitividade nacional. N esta direção, cabe ressaltar que o setor farmacêutico foi indicado pela recente "Política Industrial, Tecnológica e de Comércio Exterior" do Governo Federal ${ }^{24}$ e pelo conseqüente lançamento do Profarma do BNDES como um instrumento ativo de promoção da competitividade da indústria nacional, incluindo o incentivo às exportações, a fusões empresariais e à modernização tecnológica e na estrutura gerencial. 0 apoio pode ser dado às atividades relacionadas à produção de medicamentos (Profarma - Produção), à pesquisa e desenvolvimento (Profarma-P, D \& I) e ao fortalecimento das empresas de controle nacional (Profarma - Fortalecimento das Empresas $\mathrm{N}$ acionais). Além destes instrumentos, foi regulamentada a aprovação de incentivos fiscais dediversas naturezas para empresas que realizem pesquisa tecnológica edesenvolvimento ${ }^{25}$ e até mesmo a questão das possibilidades das compras governamentais serem direcionadas para o estímulo ao setor voltou a ser debatida nos fóruns existentes nos moldes do Buy American $\mathrm{Act}^{26}$.
N este momento, pode ser interessante olhar para a experiência dos genéricos, tentando articular a política de saúde com a política industrial. Para se atuar sobre o cerne da falta de competitividade das empresas nacionais no mercado farmacêutico e a dependência cada vez maior do país com relação às importações de medicamentos, deve-se encarar a baixa capacitação local em inovação, a base da competição naindústria. Esta situação constitui, de fato, um problema crítico para a política de saúde. Com exceção da área de vacinas, políticas bem-sucedidas de saúde se refletem em maior dependência de importações.

0 poder do Estado eo potencial das políticas públicas para incentivar o setor, mediante suas ações, explícitas ou implícitas, de promoção e de regulação, adquirem, na área da Saúde, uma abrangência dificilmente encontrada em outro grupo ou cadeia produtiva, mediante a compra de bens e serviços, os repasses de recursos para os prestadores de serviços, os investimentos na indústria e na rede assistencial e um conjunto amplo de atividades regulatórias que delimitam as estratégias dos agentes econômicos. 0 Estado constitui, assim, uma instância determinante da dinâmica industrial do complexo pelo elevado poder de compra de bens e serviços, pelo poder de indução e pelas atividades regulatórias que desempenha, numa forte interação com a sociedade civil organizada ${ }^{2}$. Este trabalho mostra que uma política específica, que ajude as empresas a antecipar e se adaptar aos fatores críticos de sucesso em seu mercado ${ }^{17}$ e que articule a dimensão sanitária à dimensão econômica, a forma de operação e organização do sistema de saúde e a dinâmica dos setores de atividade e, sobretudo, das inovaçõ̃es ${ }^{27}$ aumenta em muito suas chances de sucesso.

N esta direção, o desenvolvimento da capacidade produtiva no segmento de genéricos poderia se constituir parte de uma estratégia mais abrangente de consolidar no país uma base produtiva sólida de empresas nacionais que, ao adquirirem porte e competitividade, pudessem se qualificar para a realização de atividades mais densas do ponto de vista tecnológico, passando a investir tanto na produção de fármacos e outras matérias-primas - ainda o principal gargalo da indústria brasileira - quanto na realização de atividades de $P \& D$ que envolvam tanto os serviços tecnológicos ligados à pesquisa clínica e aos testes de equivalência farmacêutica quanto atividades com um horizonte mais longo vinculadas ao desenvolvimento incremental de processos e produtos mediante 0 estabelecimento de uma 
rede de parcerias entre empresas e instituições de pesquisa e desenvolvimento tecnológico.

Do ponto de vista da política de saúde, devese reconhecer que ainda há muito para se avançar. Em termos gerais, como se depreende, por exemplo, do Plano Nacional de Saúde ${ }^{28}$, há uma clara omissão da interface entre a política de desenvolvimento de medicamentos genéricos e a política de assistência farmacêutica, se reproduzindo, mais uma vez, a dicotomia entre o sistema de saúde e o sistema produtivo e de ciência, tecnologia einovação. A política degenéricos parece atender apenas à lógica e ao interesse, legítimo, das estratégias empresariais, não havendo um direcionamento mais consistente que procure induzir a produção nacional para os produtos de maior impacto nas condições de saúde. $\mathrm{Ou}$ seja, a política de genéricos ainda não constitui um vetor da política de saúde e suas potencialidades poderiam estar sendo melhor canalizadas para constituir um exemplo vigoroso, semelhante ao existente na área de vacinas, para aliar bemestar social, competitividade empresarial e inovação, o que é perfeitamente plausível se considerarmos que 0 gasto público federal com a assistência farmacêutica já supera 0 valor de $\mathrm{R} \$ 4$ bilhões, segundo informações levantadas no M inistério da Saúde ${ }^{29}$.

Em síntese, a política de genéricos se mostrou acertada, permitiu ganhos estáticos de aumento da oferta e redução de preços, mas ainda deve avançar no sentido desua contribuição para a superação das duas lacunas centrais do complexo industrial da saúde: a base empresarial local de inovação e o comprometimento com as condições de saúde da população brasileira.

\section{Colaboradores}

C Quental participou da concepção, delineamento e redação do artigo, análise e interpretação de dados e revisão crítica. JC Abreu participou da pesquisa, concepção, análise e interpretação dos dados e redação do artigo. JV Bomtempo e CAG Gadelha participaram do delineamento e redação do artigo, análise e interpretação de dados e revisão crítica. 


\section{Referências}

1. Associação Brasileira de Pós-Graduação em Saúde Coletiva. Política Nacional de Ciência, Tecnologia e Inovação em Saúde: uma proposta. Rio de Janeiro: Abrasco; 2002.

2. Gadelha CAG. 0 complexo industrial da saúde e a necessidade de enfoque dinâmico na economia da saúde. Rev C S Col 2003; 8(2):521-535.

3. Guimarães R. Bases para uma política nacional de ciência, tecnologia e inovação em saúde. Rev C S Col 2004; 9(2):375-387.

4. Abreu J.C. Competitividade e análise estrutural da indústria de medicamentos genéricos brasileira [dissertação]. Rio de Janeiro (RJ): Escola de Química/ UFRJ; 2004

5. Vandergrift $M$, Kanavos P. Health policy versus industrial policy in the pharmaceutical sector: the case of Canada. Health Policy 1997; 41:241-260.

6. Lei $n^{\circ} 9.787$. Altera a Lei $n^{\circ} 6.360$, de 23 de setembro de 1976, que dispõe sobre a vigilância sanitária, estabelece o medicamento genérico, dispõe sobre a utilização de nomes genéricos em produtos farmacêuticos e dá outras providências. Diário O ficial da União 1999; 11 fev.

7. Resolução RDC n०210/ANVISA. Diário Oficial da União 2003; 14 ago.

8. Resolução RDC n 47/ANVISA. Diário Oficial da União 2001; 28 mar.

9. Resolução RDC n 133/ANVISA. Diário Oficial da União. 2003; 2 jun.

10. Hasenclever L. Diagnóstico da indústria farmacêutica brasileira. Rio de Janeiro: Instituto de Economia/ UFRJ; 2002. [Projeto 914BRZ58]

11. Agência Nacional de Vigilância Sanitária. Custo de tratamento. [acessado 2005 Dez 10]. Disponível em: http://www.anvisa.gov.br/ hotsite/genericos/cidadao/custo.htm

12. Associação Brasileira das Indústrias de M edicamentos Genéricos. [acessado 2006 Jan 10]. Disponível em: http://www.progenericos.org.br

13. IMS H ealth Global Services - healthcare, pharmaceutical and chemical market. [acessado 2006 Jan 10]. Disponível em: http://www.ims-global.com

14. Albuquerque $\mathrm{E}$, Cassiolato J. As especificidades do sistema de inovação do setor Saúde: uma resenha da literatura como introdução a uma discussão sobre 0 caso brasileiro. São Paulo: Editora USP; 2000. [Estudos FeSBE I]
15. Agência Nacional de Vigilância Sanitária. [acessado 2005 Dez 10]. Disponível em: www.anvisa.gov.br/ medicamentos/equivalencia farmaceutica/index.asp

16. Agência Nacional de Vigilância Sanitária. Manual de boas práticas em biodisponibilidade e bioequivalência. [acessado 2005 Dez 10]. Disponível em: http:// www.anvisa.gov.br/medicamentos/bioequivalência/ index.asp

17. Ferraz JC, Kupfer D. Firmas em competição e política industrial. Folha de São Paulo 1995 Jan 26; p.2.

18. Langshwager ASM. A logística dos distribuidores farmacêuticos no Brasil: um estudo de caso [dissertação]. Rio de Janeiro (RJ): COPPEAD/UFRJ; 2002.

19. Security and Exchange Commission. [acessado 2003 Nov 15]. Disponível em: http://www.sec.gov

20. Combination Therapy: Novartis buys two generic drug makers. The Economist 2005; 374 (8415):71.

21. Big generic pharma: a merger creates a global giant. The Economist 2005; 376(8437):62.

22. Genérico cresce no Brasil e mira Europa. Folha de São Paulo 2004 Out 4; p. 32.

23. Universidade Estadual de Campinas. [depoimento de Dante Alário Júnior, diretor da Biolab Sanus, a Política Industrial] [acessado $2005 \mathrm{Mar}$ 05]. Disponível em: http://www.inovacao.unicamp.br/report/pol-danteala.shtml

24. Decreto Lei n 4.928. Diário Oficial da U nião 2003; $24 \mathrm{dez}$.

25. Lei n 11.196. Diário Oficial da União 2005; 21 nov.

26. Buy American Act. US Code Eletronic Edition. [acessado 2006 Fev 15]. Disponível em: http://www. access.gpo.gov/uscode

27. Gadelha CAG, Quental C, Fialho BC. Saúde e inovação: uma abordagem sistêmica das indústrias da Saúde. Cad Saúde Pública 2003; 19(1):47-60.

28. Portaria MS n 2.607. Diário Oficial da União 2004; $13 \mathrm{dez}$.

29. Brasil. Ministério da Saúde. Departamento de Assistência Farmacêutica e Insumos Estratégicos. [acessado 2006 Jul 04]. Disponível em: http:// www.anvisa.gov.br/institucional/conselho/resumo/ 22_291105_pol_af_ms-2005.ppt

Artigo apresentado em 11/07/2006

Aprovado em 26/06/2007

Versão final apresentada em 25/06/2007 